\title{
MORPHOLOGY AND SYNAPTIC CONNECTIONS OF ULTRAFINE PRIMARY AXONS IN LAMINA I OF THE SPINAL DORSAL HORN: CANDIDATES FOR THE TERMINAL AXONAL ARBORS OF PRIMARY NEURONS WITH UNMYELINATED (C) AXONS
}

\author{
STEPHEN GOBEL, ${ }^{1}$ WILLIAM M. FALLS,' AND EMMA HUMPHREY \\ Neurocytology and Experimental Anatomy Section, Neurobiology and Anesthesiology Branch, National Institute of Dental Research, \\ National Institutes of Health, Bethesda, Maryland 20205
}

\begin{abstract}
Neurons in Rexed's lamina I have the bulk of their dendritic arbors confined within this lamina. This study examines the morphology and synaptic connections of primary axons which generate axonal endings in lamina I of the spinal dorsal horn and are in position to deliver their inputs directly to lamina I neurons. Primary axons were made visible for light and electron microscopical study hy applying horseradish peroxidase (HRP) to the severed central stumps of cervical and lumbar dorsal roots and allowing sufficient time for the orthograde movement of the HRP into the terminal axonal arbors. Golgi preparations provided supplementary light microscopical views of these axons. Lamina I receives the terminal arborizations of two very different kinds of primary axons. One of these generates many ultrafine endings along unbranched, long rostrocaudally oriented, strand-like collaterals which arise from thin parent branches in Lissauer's tract. In view of these thin parent branches, most ultrafine primary axons are considered to be unmyelinated (C) primary axons. The second kind of primary axon generates large caliber endings on branched collaterals. These arise from relatively thick parent branches in Lissauer's tract which, on the basis of their size, are considered to be myelinated (A $\delta$ ) primary axons.

The scalloped endings of both primary axons lie in the interior of glomeruli where they form axodendritic synapses on small dendritic shafts and spines. It is at these synapses that these two kinds of primary axons are thought to transfer nociceptive and thermal inputs directly to the dendritic arbors of lamina I neurons. Transmitter release at these axodendritic synapses in response to primary inputs can be modified, probably diminished or inhibited, by synaptic events within the glomeruli from at least three sources. Synaptic vesicle-containing dendrites form dendroaxonic synapses on primary endings and two kinds of axons form axoaxonic synapses either on primary endings or on the intervaricose segments of the primary axons.
\end{abstract}

It has now been established through the use of anatomical and physiological techniques that Rexed's (1952) lamina I is one of the major locations of long distance projection neurons in the spinal and medullary dorsal horns (e.g., Price and Dubner, 1977; Gobel et al., 1981; Hockfield and Gobel, 1978; Willis et al., 1979 for reviews). Most lamina I neurons receive nociceptive inputs from primary neurons with small caliber axons which conduct in the $\mathrm{C}$ and $\mathrm{A} \delta$ ranges (Christensen and Perl, 1970; Kumazawa and Perl, 1978; Light et al., 1979; Bennett et

\footnotetext{
${ }^{1}$ To whom correspondence should be addressed at Neurobiology and Anesthesiology Branch, National Institute of Dental Research, National Institutes of Health, Building 30, Room B-20, 9000 Rockville Pike, Bethesda, MD 20205.

${ }^{2}$ Present address: Department of Anatomy, Michigan State University, East Lansing, MI 48824.
}

al., 1981). Some also receive innocuous inputs (Bennett et al., 1981; see Price and Dubner, 1977 for review). One of the most important current questions relating to the neural circuitry of the dorsal horn concerns the manner in which different kinds of primary afferent inputs reach lamina I neurons.

Golgi and intracellular horseradish peroxidase (HRP) studies have shown that lamina I neurons may send an occasional dendrite into the overlying white matter ( $\mathrm{Ra}$ mon y Cajal, 1911; Gobel, 1978) and that a rare lamina I neuron may send a dendrite into deeper layers of the dorsal horn (Ramon y Cajal, 1911; Beal, 1979; Light et al., 1979; Bennett et al., 1981). However, most lamina I neurons have their flattened dendritic arbors confined within lamina I (Gobel, 1978). The presence of primary axonal endings in lamina I as well as in lamina II and the deeper layers of the dorsal horn suggests that primary 
inputs could reach lamina I neurons over two routes: directly on their dendrites in lamina 1 and indirectly via an excitatory interneuron (Gobel, 1979).

Recently, a number of studies using several different experimental approaches have addressed the question of the termination sites of $\mathrm{A} \delta$ and $\mathrm{C}$ primary axons in laminae I and II. These studies have led to two different interpretations as to how these axons are distributed in these laminae. One interpretation is based on light (La Motte, 1977) and electron microscopical (EM) (Ralston and Ralston, 1979) degeneration studies as well as on studies in which physiologically identified A $\delta$ primary axons were injected intra-axonally with HRP (Light and Perl, 1979) and electrophysiological studies of neurons in laminae I and II (Kumazawa and Perl, 1978; Light et al., 1979). These studies suggest that $C$ primary axons terminate predominantly in lamina II and that $A \delta$ primary axons terminate in lamina $I$. The second interpretation is based on EM degeneration studies (Gobel and Binck, 1977) and on studies in which primary axons were filled with HRP (Gobel and Falls, 1979) and suggests that lamina $I$ is an important termination site of $C$ primary axons and lamina II is an important termination site of A $\delta$ primary neurons. While neither of these interpretations in their original conception precluded the other, they are nonetheless frequently thought of as mutually exclusive and remain at the heart of one of the major issues in the neural circuitry of the dorsal horn.

The present study was undertaken because earlier independent studies identified two kinds of primary endings in lamina I. One was a very small ending (Gobel and Binck, 1977; Gobel and Hockfield, 1977) and the other was a relatively large ending (Light and Perl, 1979; Ralston and Ralston, 1979). Such observations suggested that lamina I may not simply receive the terminal arbors of a single kind of primary axon but that two or more different kinds of primary axons may terminate there. If this were in fact the case, it would help to clarify some of the earlier above mentioned disparate views which intimated that lamina I received the terminal arbors of only a single kind of primary neuron.

Recently, horseradish peroxidase (HRP) has been applied to the central portions of severed dorsal roots in order to fill primary axons and demonstrate different morphological aspects of primary axons in the spinal cord (Light and Perl, 1977; Proshansky and Egger, 1977; Beattie et al., 1978; Gobel and Falls, 1979). This method has several important advantages over more traditional degenerative techniques for studying primary axons in the spinal cord. First, filling of the primary axons with HRP occurs relatively quickly. This makes it possible to use short postoperative survival times following dorsal root rhizotomy, i.e., less than 1 day, so that primary axons can be viewed before they fragment or become detached from their synaptic connections. This obviates the difficulties in interpreting small endings as such or as degenerating fragments of larger endings. Second, it displays large numbers of primary endings in contrast to the relatively small number of degenerating primary endings seen at any given postoperative survival time since all primary axons do not degenerate at the same time. Third, prinuary endings can be viewed in the light microscope as well as in the electron microscope.
This study shows that lamina I receives the terminal arborizations of two kinds of primary axons, both of which are thought to deliver nociceptive inputs to the dendrites of lamina I neurons. One of these, the ultrafine axon, generates the smallest primary endings thus far uncovered in the spinal cord and these are thought to originate from nociceptive primary neurons with unmyelinated (C) axons. The other one contains large caliber endings and thick parent branches of the size of small (A\&) myelinated axons. The morphology of their endings and their branching pattern suggest that they belong to the small myelinated A $\delta$ high threshold mechanoreceptive primary axons which have been shown to terminate in part in lamina I (Light and Perl, 1979).

\section{Matcrials and Methods}

Four adult cats were anesthetized deeply with sodium pentobarbital. Cervical laminectomies were performed in two cats in order to expose the cervical dorsal roots, while lumbar dorsal roots were exposed in the other two cats following lumbar laminectomies. Either all cervical or all lumbar dorsal roots on one side then were severed approximately midway between the spinal cord and their dorsal root ganglia. Crystalline HRP (Sigma type VI) then was either placed directly on the cut roots or crushed into them with fine rat-toothed forceps. Then small drops of saline were applied from a fine injection needle to dissolve the HRP and to keep the dorsal roots moist. The HRP was kept on the cut central ends of the dorsal roots for $8 \mathrm{hr}$ in both cervical root experiments and for 6 and $12 \mathrm{hr}$ in the two lumbar root experiments. Subsequently, the cats were perfused with a solution containing a $0.12 \mathrm{~m}$ phosphate buffer, $1 \%$ glutaraldehyde, and $1 \%$ paraformaldehyde. Following the perfusion, the appropriate segments of spinal cord were cut into blocks containing one to three dorsal roots and then stored in the same fixative overnight. The following day, the blocks were cut on an Oxford Vibratome into $100-\mu \mathrm{m}$ sections in the parasagittal plane in the case of the lumbar segments and in planes ranging from horizontal to parasagittal in the case of the cervical segments. Next the sections were rinsed in phosphate buffer and immediately processed with diaminobenzidine and $\mathrm{CoCl}_{2}$ (Adams, 1977) for $\mathrm{HRP}$ reaction product. The sections then were dehydrated in a graded series of glycerin solutions (Gobel et al., 1980), transferred to pools of $100 \%$ glycerin on glass slides, and coverslipped. After preliminary examination, some of the sections were processed for EM analysis according to a procedure described elsewhere (Gobel et al., 1980) and then thin-sectioned in either the parasagittal or horizontal plane. With the exception of some small dendrites which exhibit signs of internal membranous degenerative changes (Figs. $9 a$ and 11), the neuropil remained well preserved despite having passed through the histochemical incubation solutions and glycerin prior to osmication. The rest of the $100-\mu \mathrm{m}$ sections were rehydrated in a descending series of glycerin solutions, then dehydrated in ethanol, cleared in xylene, and mounted in Permount for light microscopical study. Camera lucida drawings were made using a Zeiss light microscope which was fitted with a $\times 100$ long working distance lens, a $\times 1.6$ auxiliary magnifying lens (Optivar) which was mounted above the objective lens turret, a Zeiss drawing tube 
which was mounted above the Optivar, and $\times 10$ oculars. This arrangement provided a final magnification of $x$ 1600 which was sufficient to visualize and reproduce accurately the widths of the finest unmyelinated portions $(\sim 0.3 \mu \mathrm{m})$ of the HRP-filled primary axons.

In addition, thick sections (150 to $300 \mu \mathrm{m}$ ) were cut by hand in either the horizontal or parasagittal planes from Golgi preparations (see Gobel, 1978 for preparative details) of the cervical dorsal horn. These sections were used to examine the course and morphology of axons suspected of being primary axons in lamina $I$ and in Lissauer's tract. In the drawings made from the Golgi and HRP specimens, the line at the right denotes the border between lamina I and either Lissauer's tract or the dorsal funiculus. The scale bars in the drawings represent $10 \mu \mathrm{m}$ and the scale bars in the electron micrographs represent $0.5 \mu \mathrm{m}$.

\section{Results}

Ultrafine primary axons. Two kinds of HRP-filled primary axonal endings are seen light microscopically in the 100- $\mu \mathrm{m}$ HRP sections-large elliptical endings, measuring $1 \times 2 \mu \mathrm{m}$ or larger (Fig. 2), and much finer spherical and elliptical endings, most of which measure less than $0.5 \mu \mathrm{m}$ across their short diameter (Figs. 1 and 2 ). The latter endings are the smallest primary endings found thus far in the spinal or medullary dorsal and ventral horns and will be referred to as the ultrafine primary endings.

Ultrafine primary endings are found throughout lamina $I$ in two patterns, i.e., occasionally in small clusters and most commonly in rows of varying length (Fig. 1). Within these rows, 10 to 15 endings may be visible at a single focal plane (Fig. 2). Most of the endings in the clusters can be resolved into rows of endings with small changes in focal plane.

Both patterns can be found in electron micrographs. Figure 3 illustrates five closely spaced, HRP-filled, ultrafine primary endings. The ability to section through so many endings strongly suggests that they are connected and are part of the same axonal branch. The two endings at the right are shown to be connected in an adjacent section (see Fig. 9a) and several other examples of connections between adjacent ultrafine endings have been observed (Fig. 5). The cluster pattern is illustrated in Figure 4 where six ultrafine endings surround a lamina I neuronal cell body. Although ultrafine endings are found frequently in the vicinity of cell bodies, they have never been seen synapsing on them.

Figures 5 and $9 a$ demonstrate that neighboring ultrafine endings are linked by thin intervaricose segments and are part of the same axon. At the light level, the intervaricose segments, while occasionally visible, usually are not seen because the relatively small amount of HRP present in these segments does not provide for sufficient contrast to distinguish them from the background neuropil (Figs. 1 and 2). However, when lamina I is examined in the parasagittal or horizontal planes in Golgi preparations, many examples of ultrafine axons can be seen in which the axonal endings as well as the intervaricose segments are clearly visible (Figs. 6 and 7). The Golgi reaction product stands out sharply against the background and shows that one kind of ultrafine axon consists of fine strands ( $0.3 \mu \mathrm{m}$ or less in diameter) along which are strung numerous small closely spaced ultrafine endings. The endings vary in shape from spherical to highly elliptical forms which are more than twice as long as they are wide (Fig. 6). The most common pattern of endings along an ultrafine axon is a group of two to five or more of the smallest spherical endings preceded and followed by a somewhat larger elliptical form. This pattern also can be seen at the light level in the $100-\mu \mathrm{m}$ HRP sections (compare Figs. 1 and 6). Side branching along that portion of an ultrafine axon bearing endings is rare and, when it does occur, the side branch is very short and usually contains only one or two endings (Fig. 6).

A few ultrafine axons in both Golgi and HRP specimens have been traced back into Lissauer's tract (Figs. 7 and 8). Within Lissauer's tract, the preterminal or parent branches of the ultrafine axons are the same caliber as their ending-bearing segments in lamina I, i.e., $\sim 0.3$ to $0.5 \mu \mathrm{m}$ in diameter, which corresponds to the diameters of most of the unmyelinated axons that have been seen in electron micrographs of Lissauer's tract (K. Chung et al., 1979; Gobel and Falls, 1979). The preterminal segments in Lissauer's tract undergo many sharp bends every few micrometers and, with one possible exception (Fig. 8), do not bear endings. During the course of the study, large numbers of ultrafine axons were followed for long distances in Golgi specimens where these thin axons as well as thicker ones $(1.0 \mu \mathrm{m}$ and larger in diameter), which are probably myelinated (Figs. 18 and 19), are clearly visible. Ultrafine axons could never be traced back to these thicker axons either in lamina I or in Lissauer's tract. This suggests that the ultrafine axons are continuations of the unmyelinated primary axons in Lissauer's tract.

EM analysis of the endings of the HRP-filled ultrafine primary axons shows that they are scalloped endings which have several other neural processes impressed into their surface. Many ultrafine primary endings are almost fully surrounded by neural processes and lie in the interior of small glomeruli. Within these glomeruli, eight different kinds of processes surround the primary endings. These include three kinds of dendritic processes, two kinds of axonal endings, a pale process with numerous dense core vesicles, unmyelinated axons, thick filament-filled astrocytic processes, and sheet-like astrocytic processes. The dendrites receive slightly asymmetrical axodendritic synapses from the primary ending (Figs. 5, $9, a$ and $d$ and 10). The most common dendritic processes are fine spine heads $(S)$ which may contain mitochondria (Fig. 9d), tubular forms of agranular reticulum (Fig. 9d), and an occasional dense core vesicle (Fig. 9d) but do not contain aggregates of agranular synaptic vesicles.

These $\mathbf{S}$ spines, in addition to receiving axodendritic synapses from the primary endings, also receive dendrodendritic synapses from adjacent dendritic spine heads which contain synaptic vesicles. These vesicle-containing spines $\left(S_{v}\right)$ are small, turgid structures with a more or less spherical or slightly elliptical shape and a pale cytoplasm (Fig. 9, $a$ and $b$ ). When $S_{\mathrm{v}}$ spines can be traced back to their parent dendritic shafts, they are seen to arise from thin necks through which pass a few neurotubules and tubular forms of agranular reticulum (Fig. $9 b$ ). The $S_{v}$ spines contain a mixture of different sized 

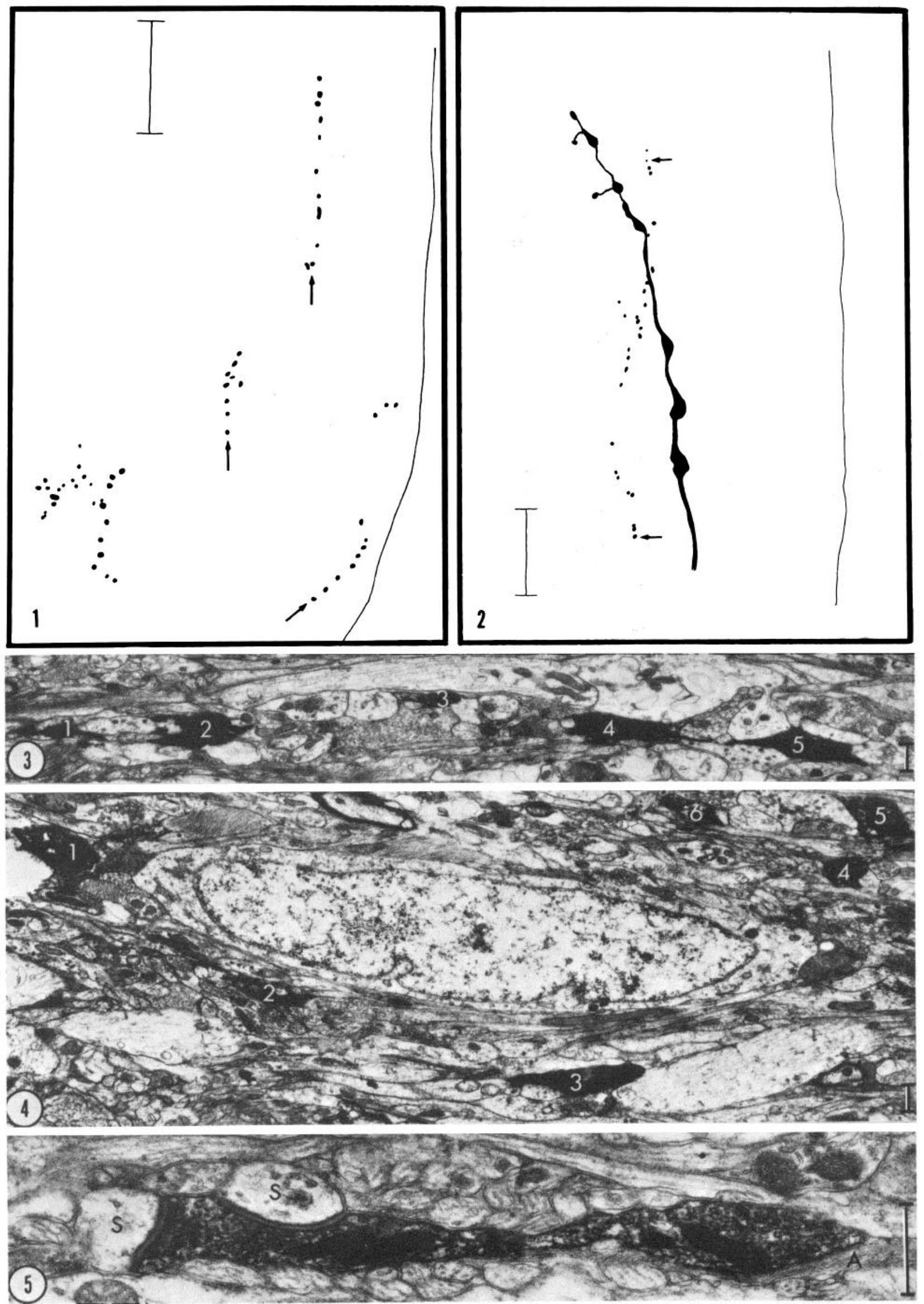
small synaptic vesicles which include small spheres and ellipses as well as highly flattened ones whose long diameters are at least twice that of their small diameters. They also contain a few dense core vesicles. An important feature which distinguishes these $S_{v}$ spines from other synaptic vesicle-containing processes in the lamina I glomeruli is that their synaptic vesicles are typically found in small focal clusters and do not fill out all parts of the spine head (Figs. 9, $a$ to $d$ and 10). These clusters typically are found along the cell membrane at synapses (Figs. 9, $a$ and $d$ and 10) as well as in the interior of the spine head. $S_{v}$ spines form short symmetrical dendrodendritic synapses on adjacent $S$ spines (Fig. $9 d$ ). They also synapse on extremely fine (0.1- to $0.3-\mu \mathrm{m})$ structures (Fig. $9 a$ ) which are postsynaptic to primary endings at asymmetrical synapses (Fig. 9b) and therefore are considered to be fine caliber dendrites. At their dendrodendritic synapses, the smooth contour of the $S_{\mathrm{v}}$ spines becomes either somewhat flattened (Fig. 9d) or somewhat concave (Fig. 9a, right inset) where it embraces the postsynaptic dendrite.

The $\mathrm{S}_{\mathrm{v}}$ spines also synapse on the primary ending at dendroaxonic synapses (Figs. $9 d$ and 10). These dendroaxonic synapses always appear relatively short in single micrographs, i.e., about 0.1 to $0.2 \mu \mathrm{m}$, in contrast to the somewhat longer axodendritic synapses of the primary ending which can attain lengths of 0.5 to $0.6 \mu \mathrm{m}$ (Fig. 9d). The dendroaxonic synapses are characterized by a small cluster of synaptic vesicles at the presynaptic membrane, an absence of conical presynaptic densities, and a synaptic cleft which contains some dense material and is either the same width as or only slightly wider than the adjacent intercellular space (Figs. 9d and 10). These dendroaxonic synapses, like their counterparts in lamina II (Gobel, 1976), are shorter than the adjacent axodendritic synapses. Although the presence of the dense HRP reaction product within the primary ending precludes the determination of the presence of postsynaptic dense material at the dendroaxonic synapses, postsynaptic densities have never been seen subjacent to the axolemma of scalloped endings in normal material. Therefore, these dendroaxonic synapses are considered symmetrical. Dendroaxonic synapses are found in the depths of the scalloped depressions in a primary ending (Figs. $9 d, 10$, and 14) as well as along the rim of these depressions (Fig. 9a, right inset). A final characteristic of the $S_{v}$ spines is that they receive synapses only from primary endings (Fig. 9a), whereas $\mathrm{S}$ spines receive synapses from non-primary endings as well (Fig. $9 d$ ).

The ultrafine primary endings also form asymmetrical synapses on small dendritic shafts (Figs. 9a and 10). These shafts possess the typical characteristics of higher order dendrites, i.e., they are relatively fine, with diameters of $1.5 \mu \mathrm{m}$ or less, and they contain neurotubules, a few elongated mitochondria, and vesicular and tubular forms of agranular reticulum but lack granular endoplasmic reticulum or polysomes (Fig. 10). In Figure 9, $a$ and $b$ show that some dendrites which give rise to $S_{\mathrm{v}}$ spines receive primary inputs on their shafts as well as on their spine heads from the same primary axon.

Two other processes which contain synaptic vesicles also are found around the perimeter of lamina I glomeruli built around ultrafine primary axonal endings (see $P_{1}$ and $P_{2}$ in Figs. $9 d$ and 10). Since they have never been seen receiving synapses from the primary endings, they are thought to be axonal endings. They differ from the $S_{v}$ spines in several respects: they generally have more elongated irregular shapes; their cytoplasm in most instances is somewhat darker than that of the $S_{v}$ spines; their synaptic vesicles, rather than being clustered, are dispersed more evenly throughout the entire ending; and their synapses on dendrites exhibit rows of prominent conical presynaptic densities (Figs. $9 d$ and 10), whereas $S_{v}$ spines either lack them entirely or, rarely, contain a single one. These endings generally resemble the small $\mathrm{P}$ endings surrounding primary endings in the lamina II glomeruli (Gobel, 1974).

Two distinct kinds of these peripheral or $P$ axonal endings can be distinguished on the basis of the morphological appearance of their synaptic vesicles. One of these (Fig. 9d) has the same kind of synaptic vesicles found in the $S_{v}$ spine heads, i.e., a mixture of small spherical and elliptical vesicles with a substantial number of flattened ones. This ending will be designated as the $P_{1}$ ending. The second one, which will be called the $\mathrm{P}_{2}$ ending (Fig. 10 ), also contains a mixture of spherical and elliptical

Figure 1. HRP-filled, spherical and elliptical ultrafine primary endings are found throughout lamina I. They are seen in small clusters such as the one at the lower left and aligned in rows (arrows). The thin connecting intervaricose segments usually are not seen at the light level. Scale bar, $10 \mu \mathrm{m}$.

Figure 2. This field contrasts the size of the ultrafine primary endings with those of the large caliber primary axons and shows that both axons are found close to each other in lamina I. Ten or more ultrafine primary endings typically can be seen at a single focal plane. All of the HRP-filled endings between the arrows were visible at a single focal plane. Scale bar, $10 \mu \mathrm{m}$.

Figure 3. Five aligned black HRP-filled ultrafine primary endings (1 to 5) span a distance of $16 \mu \mathrm{m}$ in the rostrocaudal axis of lamina I. All are probably part of the same axon and the connection between endings 4 and 5 is shown at higher magnification in Figure 9a. Magnification $\times 9,100$. Scale bar, $0.5 \mu \mathrm{m}$.

Figure 4. Six HRP-filled ultrafine primary endings ( 1 to 6 ) are grouped around the cell body of a small lamina I neuron. Ultrafine or large primary endings have never been found synapsing on lamina I neuronal cell bodies. Magnification $\times 10,600$. Scale bar, $0.5 \mu \mathrm{m}$.

Figure 5. Two elliptical HRP-filled ultrafine primary endings are connected by a short thin intervaricose segment. Two spine heads $(S)$ without synaptic vesicles are pressed into shallow scalloped depressions in the left primary ending where they receive slightly asymmetrical axodendritic synapses from the primary ending. These primary endings are comparable in size, shape, and proximity to those seen at the light level, such as those in Figure 1. A, Sheet-like astrocytic process. Magnification $\times 31,500$. Scale bar, $0.5 \mu \mathrm{m}$. 


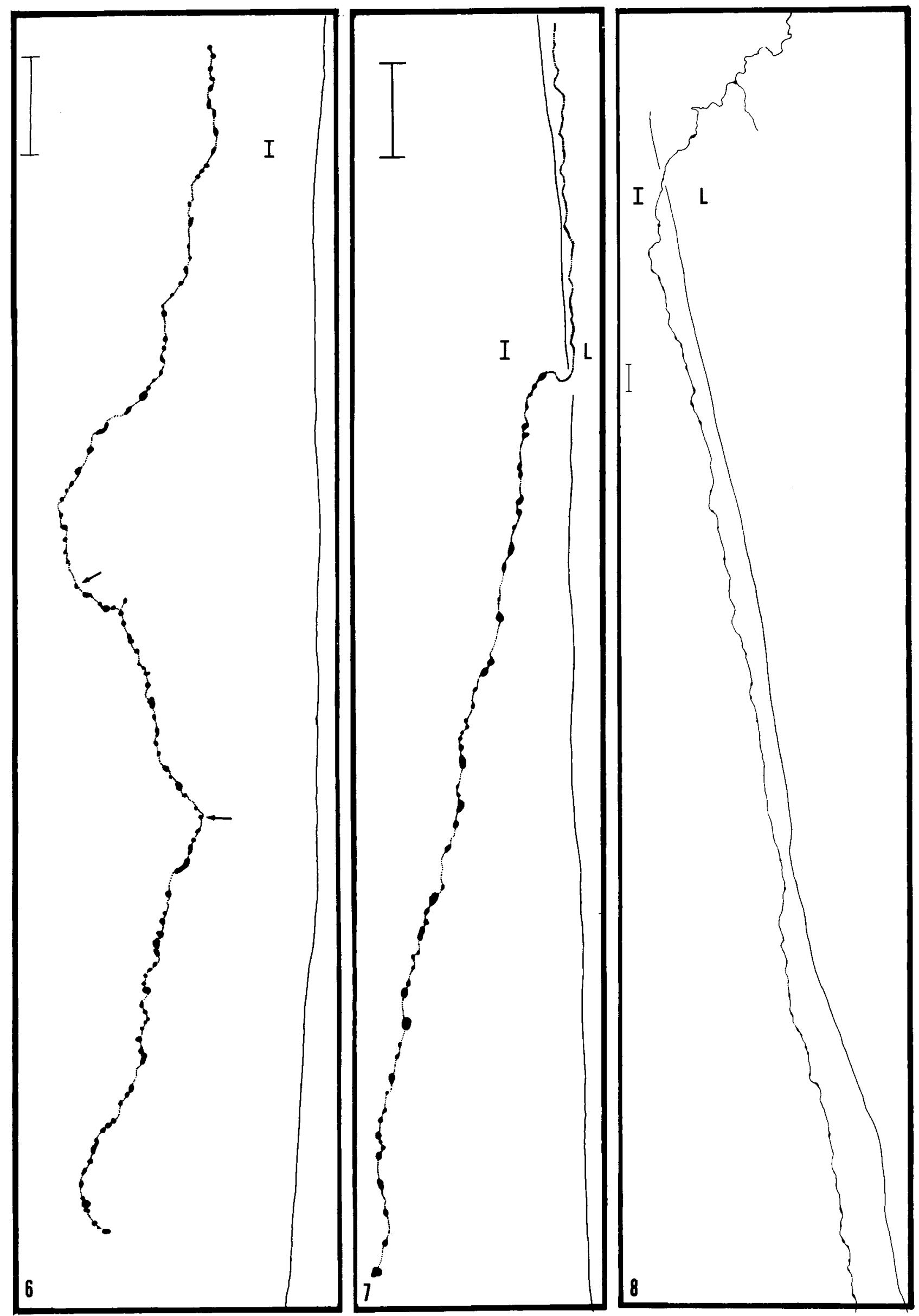


vesicles but with many more larger ellipses than the $P_{1}$ ending. In contrast to the $\mathrm{P}_{1}$ ending, the $\mathrm{P}_{2}$ ending has relatively few flattened vesicles.

$P$ endings have been found in the following synapses in the lamina I glomeruli. $\mathrm{P}_{1}$ endings form symmetrical (Fig. 9d) and slightly asymmetrical (Fig. 15) axodendritic synapses on $\mathrm{S}$ spine heads and axoaxonic synapses on ultrafine primary axons (Fig. 9a). $\mathrm{P}_{2}$ endings form asymmetrical axodendritic synapses on dendritic shafts (Fig. 10 ) and axoaxonic synapses on ultrafine primary axons (Fig. 14). The axoaxonic synapses are probably symmetrical. Here again, although the HRP reaction product would obscure postsynaptic densities, such densities have not been seen in scalloped endings in normal material.

Three other kinds of processes commonly enter these glomeruli and become impressed into the surface of ultrafine primary endings. These include smoothly contoured pale processes which contain numerous large dense core vesicles and variable amounts of agranular vesicles (Fig. 9c). Their smooth contours and pale cytoplasm suggest that they may be dendritic spines. However, they have not been found in synaptic contact with either the primary ending or with the other components of the glomeruli. Many of the clusters of extremely small processes that the ultrafine primary axons pass through are undoubtedly unmyelinated axons (Fig. 5), with some of these being other primary axons (Fig. 9, $a$ and $c$ ). Some, however, receive asymmetrical synapses from ultrafine primary endings and may be fine dendrites (Fig. $9 b$ ). Large filament-filled glial processes, which are very common in lamina I, especially in its most superficial parts, are found frequently impressed into ultrafine primary endings (Fig. 15). No synaptic or junctional specializations have ever been found between these glial processes and the primary endings. Finally, appreciable portions of the surface of ultrafine primary endings are covered by fine sheet-like astrocytic processes which may (Fig. 5) or may not (Fig. 10) contain filaments.

A second kind of ultrafine primary axon also courses in lamina I (Fig. 8). It differs from those in Figures 6 and 7 in that it contains many fine highly elongated endings but relatively few spherical ones. In addition, the endings are generally much more widely spaced although two or three endings are occasionally found within a $10-\mu \mathrm{m}$ length of axon. The HRP-filled ultrafine primary axon in Figure 8 is traced from Lissauer's tract where it originates from a fine parent branch which is about $0.3 \mu \mathrm{m}$ in diameter. In Lissauer's tract, it bifurcates once and follows a tortuous undulating course. The diameters of the two daughter branches are the same as that of the parent branch. Once it enters lamina I, it becomes aligned in the rostrocaudal axis close to the outer border of lamina I and was followed for $965 \mu \mathrm{m}$, of which only the first 424 $\mu \mathrm{m}$ are illustrated. It does not bifurcate or generate any side branches.

An EM search of parasagittal sections has identified many highly elongated, elliptical, HRP-filled primary endings which fit the dimensions of some of the endings in Figure 8. Some of the longest ones measure $5.4 \mu \mathrm{m}$ in length (Fig. 14) but only $0.5 \mu \mathrm{m}$ or less across their short diameter. These highly elongated primary endings have thin unmyelinated intervaricose segments (Fig. 12) and, like their shorter counterparts in Figures 5, 9, and 10, are scalloped endings which lie in the interior of glomeruli (Figs. 13 and 14). Within these highly elongated glomeruli, the primary ending is surrounded by the same kinds of neural processes that make up the smaller primary glomeruli, i.e., $\mathrm{S}$ spines (Fig. 13), $\mathrm{S}_{\mathrm{v}}$ spines (Fig. 14), dendritic shafts (Fig. 11), and P axonal endings (Fig. 14), pale processes with many dense core vesicles (Fig. 11), and unmyelinated axons (Fig. 12).

Large caliber primary axons. The lamina I neuropil also contains many large primary endings (Figs. 16, 20, and 21). Most of these have an ellipsoidal shape and measure $1.0 \mu \mathrm{m}$ or larger across their short diameter and 3 to $4 \mu \mathrm{m}$ or more in length. An analysis of parasagittal and horizontal sections of lamina I in the HRP-cut root experiments and in Golgi specimens indicate that these large endings originate from an entirely different kind of primary axon, i.e., an axon with a thick (1.0- to $1.5-\mu \mathrm{m}$ in diameter) parent branch (Figs. 17 to 19). These axons can be followed for considerable distances in Lissauer's tract and lamina I where they typically run for distances up to several hundred micrometers in one direction and then sharply reverse directions at hairpin turns only to run back in the direction from which they came (Fig. 19). The parent branches of these axons branch frequently in Lissauer's tract without appreciable changes in diameter (Fig. 17). They ultimately wend their way through Lissauer's tract and enter lamina I where some of the branches continue to reverse direction (Figs. 17 and 18) and divide. In lamina I and perhaps also in the deeper parts of Lissauer's tract, they give rise to several thin collaterals $(0.1$ to $0.5 \mu \mathrm{m}$ in diameter) which bear the large endings. These collaterals are distinguished from the ultrafine primary axons by two features in addition to the larger size of their endings. They generate their endings over much shorter lengths (Figs. 17 and 18) than

Figure 6. An ultrafine axon in lamina $I(I)$, when filled with Golgi reaction product, demonstrates its thin intervaricose segments. One hundred three closely spaced endings are found along this $120-\mu \mathrm{m}$ length of axon. The axon gives rise to only one short side branch which bears a single ending. All of the endings between the arrows were visible at a single focal plane. Scale bar, $10 \mu \mathrm{m}$.

Figure 7. This ultrafine axon is filled with Golgi reaction product. Its thin parent branch, after running in the long axis of Lissauer's tract $(L)$, turns sharply and enters lamina $I(I)$ where it gives rise to numerous ultrafine endings. The parent branch and the intervaricose segments measure about $0.3 \mu \mathrm{m}$, which corresponds to the diameters of most of the unmyelinated axons in both lamina I and Lissauer's tract. Scale bar, $10 \mu \mathrm{m}$.

Figure 8 . The thin parent branch $(\sim 0.3 \mu \mathrm{m}$ in diameter) of this HRP-filled ultrafine primary axon branches once and takes a somewhat erratic course through Lissauer's tract $(L)$. It enters lamina $I(I)$ and runs rostrally in lamina $I$, without branching, for $965 \mu \mathrm{m}$-well beyond the bottom of the figure. It differs from the ultrafine axons in Figures 6 and 7 in that its endings are more highly elongated and more widely spaced along the axon. Scale bar, $10 \mu \mathrm{m}$. 

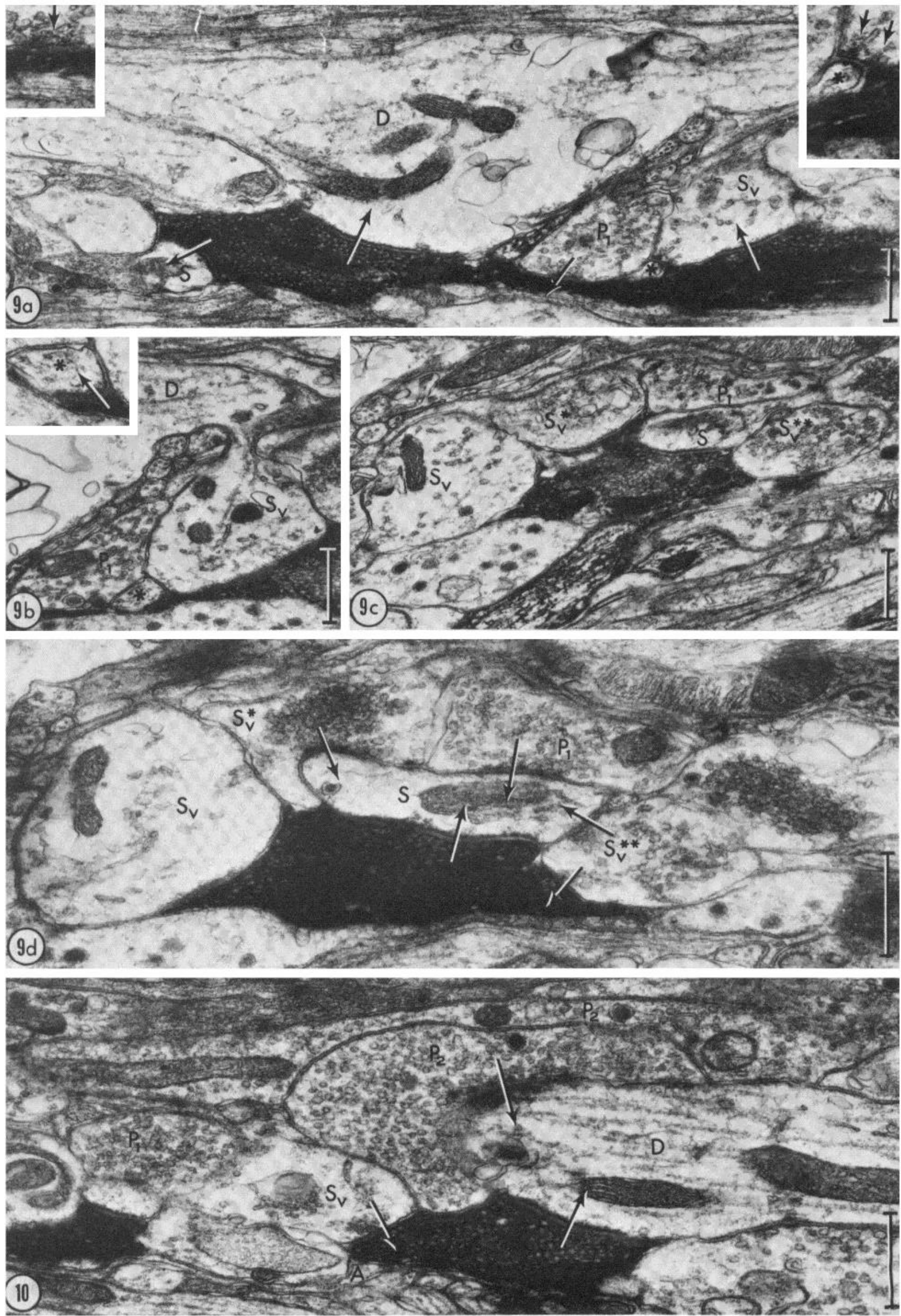
the ending-bearing segments of ultrafine axons. For example, all 13 endings of the fine collateral in Figure 18 are generated over a distance of $60 \mu \mathrm{m}$, whereas ultrafine axons generate their endings over much longer lengths, e.g., $120 \mu \mathrm{m}$ for the ultrafine axon in Figure 6 and $965 \mu \mathrm{m}$ for the axon in Figure 8. The ending-bearing segments of the larger caliber primary axons typically branch, while the ultrafine axons do not. At these branch points, one of the daughter branches usually will reverse direction and travel back toward its parent branch (Fig. 18). The recurrent daughter branch typically generates fewer endings than the daughter branch which continues on in the direction of its parent branch (Figs. 17 to 19). Some of the large endings, especially terminal ones, frequently will give off small spine-like extensions (Figs. 2 and 21).

Although large caliber primary axons generate endings throughout lamina I (Fig. 16) and share common territories with ultrafine primary axons in lamina I (Fig. 2), they probably generate their endings in a much more focal manner than the ultrafine axons. For example, the large caliber primary axon in Figure 19, although covering almost $700 \mu \mathrm{m}$ in the rostrocaudal axis, generates its endings in three relatively small foci. Three separate fine collaterals (Fig. 19, arrows 4) converge and generate their endings in a common focus. From depth measurements made with the fine focus knob of the light microscope, all of the endings in this focus are located within $29 \mu \mathrm{m}$ of each other in the transverse plane, i.e., at right angles to the page.

EM observations confirm the existence and appearance of these large primary endings in lamina I (Figs. 20 and 21). Like the ultrafine primary endings, they expand from thin intervaricose segments, a portion of which is visible in Figure $20 a$, and they lie in the interior of glomeruli (Figs. $20 b$ and 21). The neural processes surrounding the large primary endings are similar to the ones surrounding the ultrafine primary endings and include dendritic spines with $\left(S_{\iota}\right)$ and without $(S)$ synaptic vesicles (Fig. 20, $a$ and $b$ ), dendritic shafts (Figs. $20 b$ and 21 ), and $P_{1}$ endings (Fig. 20b).

\section{Discussion}

Identity of the large caliber and ultrafine primary axons. One of the major findings of this study is that lamina I receives the terminal arborizations of two morphologically distinct kinds of primary axons. These two primary axons differ in the length and branching pattern of their ending-bearing collaterals, in the distribution of their endings along these collaterals, in the size of their endings, and in the diameter of their parent branches (compare Figs. 6 to 8 with Figs. 17 to 19). The ultrafine primary axons are thought to arise from the smallest primary neurons, i.e., those with either unmyelinated or possibly extremely small myelinated axons, while the large caliber primary axons are undoubtedly myelinated and comprise part of the contingent of small A $\delta$ myelinated axons. On the basis of measurements made on the long diameters of cross-sectioned axons in Lissauer's tract (S. Gobel, W. M. Falls, and E. Humphrey, unpublished observations), one cannot simply divide the two kinds of axons into unmyelinated and myelinated groups since there is a slight overlap in the diameters of the largest unmyelinated axons and the smallest myelinated axons (without their myelin sheaths) in the vicinity of 0.5 to $0.6 \mu \mathrm{m}$. Nonetheless, ultrafine primary axons with parent branches measuring $0.3 \mu \mathrm{m}$ are almost certainly unmyelinated while large caliber primary axons with parent branches measuring $1.0 \mu \mathrm{m}$ or more are almost certainly myelinated.

Several observations suggest that the ultrafine and large caliber primary axons may fit in the $\mathrm{C}$ and $\mathrm{A} \delta$ neurophysiological calegories, respectively, for primary axons. To date, the terminal arborizations of several different kinds of myelinated primary axons which ramify in the dorsal and ventral horns have been characterized. These include the high threshold mechanoreceptor which arborizes in laminae $\mathrm{I}$ and $\mathrm{V}$ and around the central canal (Light and Perl, 1979), the small myelinated axons which generate their endings in lamina II (Beal and Fox, 1976; Gobel and Falls, 1979), the D-hair follicle afferent which

Figure 9. Serial sections through two endings and a thin intervaricose segment of an HRP-filled ultrafine primary axon in lamina I which illustrate the form and synaptic connections (arrows) of the ultrafine glomerulus. $a$, The left primary ending forms slightly asymmetrical axodendritic synapses on a dendritic shaft $(D)$ and on a spine head $(S)$ without synaptic vesicles. The primary ending at the right forms a slightly asymmetrical axodendritic synapse on a spine head $\left(S_{v}\right)$ which contains scattered synaptic vesicles which do not fill out the spine head. The $S_{v}$ spine in turn synapses (upper right inset) on a small dendrite (*) and on the crest of a scalloped depression in the primary ending. A $P_{1}$ axonal ending forms an axoaxonic synapse (shown at higher magnification in the upper left inset) on the intervaricose segment of the primary axon. Magnification $\times 26,600 ;$ insets, $\times 50,000$. Scale bar, $0.5 \mu \mathrm{m} . b$, The $\mathrm{S}_{\mathrm{v}}$ spine of $a$ originates from the dendritic shaft $(D)$ by a short thin neck. The small dendrite $(*)$ receives an asymmetrical synapse (inset) from the primary ending. Magnification $\times 26,600$; inset, $\times 70,000$. Scale bar, $0.5 \mu \mathrm{m}$. $c$, The scalloped primary ending at the right in $a$ is almost fully surrounded by small neural processes. These include, starting at the lower left, an unidentified process with numerous dense core vesicles, the $S_{v}$ spine of $a$ and $b$, a second $S_{v}$ spine head $\left(S_{v}^{*}\right)$, a $P_{1}$ axonal ending, a $S$ spine head, and a third $S_{v}$ spine head $\left(S_{v}^{* *}\right)$. Two other HRP-filled primary axons are seen at the bottom of the field. Magnification $\times 26,000$. Scale bar, $0.5 \mu \mathrm{m}$. $d$, This serial section illustrates the synaptic connections of some of the components of the glomerulus identified in $c$. The primary ending and the $P_{1}$ ending form asymmetrical and symmetrical synapses, respectively, on the $S$ spine head. Two of the $S_{v}$ spine heads $\left(S_{v}^{*}, S_{v}^{* *}\right)$ form symmetrical dendrodendritic synapses on the $S$ spine and one of these $\left(S_{v}^{* *}\right)$ forms a dendroaxonic synapse on the primary ending in the depths of scalloped depression. Magnification $\times 39,700$. Scale bar, $0.5 \mu \mathrm{m}$.

Figure 10. In this glomerulus, an HRP-filled ultrafine primary ending forms an asymmetrical axodendritic synapse on a small dendritic shaft $(D)$ which also receives an asymmetrical axodendritic synapse from a $P_{2}$ axonal ending that exhibits evenly spaced conical presynaptic densities. A $S_{v}$ spine with two small foci of small synaptic vesicles forms a dendroaxonic synapse on the primary ending. A second $P_{2}$ axon courses across the top of the field and a $P_{1}$ ending with its small synaptic vesicles lies at the left. $A$, Astrocytic process. Magnification $\times 35,400$. Scale bar, $0.5 \mu \mathrm{m}$. 

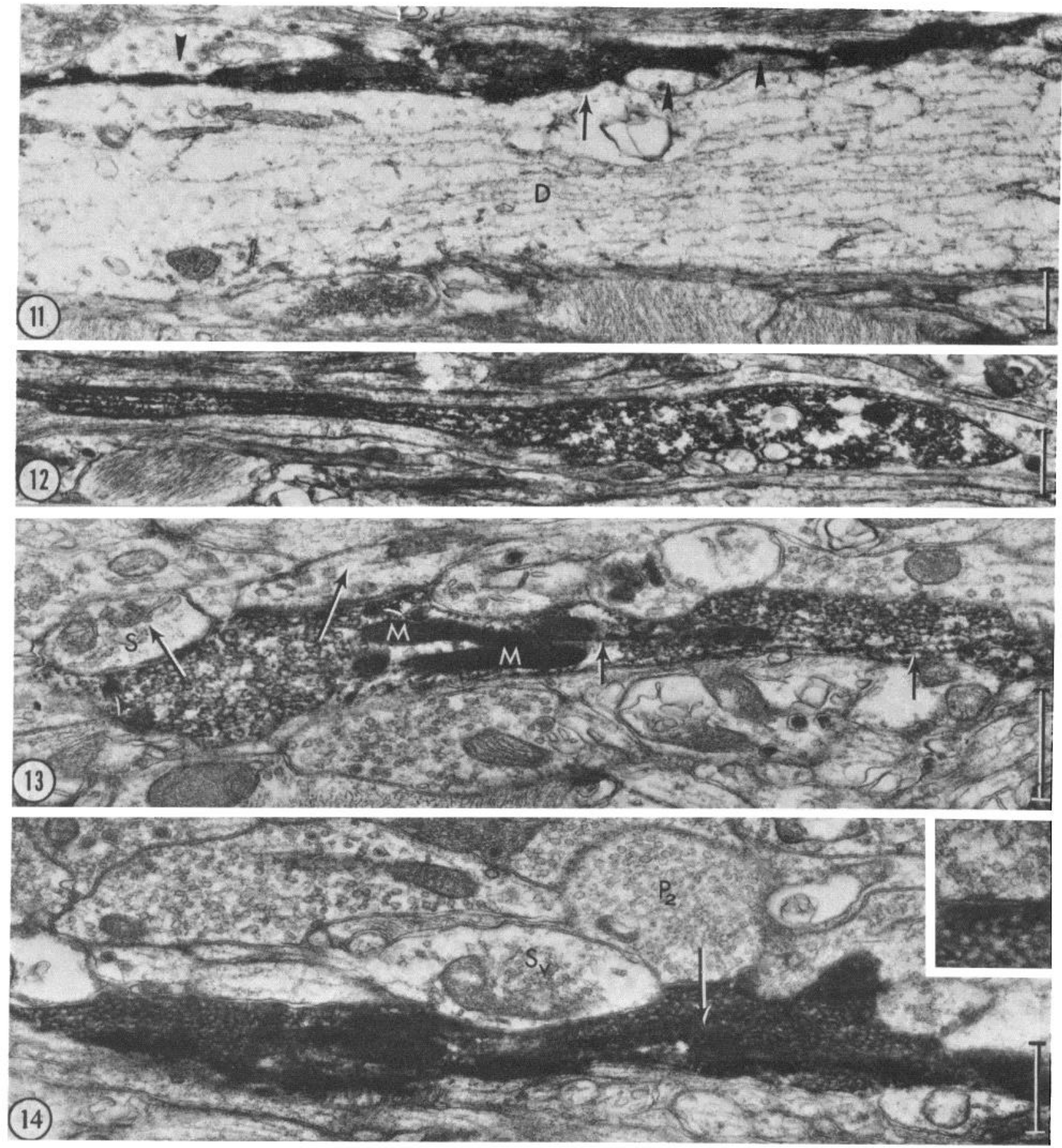

Figures 11 and 12. Examples of highly elongated HRP-filled ultrafine primary endings. In Figure 11, the primary ending embraces three small neural processes in scalloped depressions (arrowheads) and runs along a dendritic shaft $(D)$ on which it forms a small synapse (arrow). In Figure 12, a thin unmyelinated intervaricose segment expands into a highly elongated ultrafine primary ending. The ending measures $3.7 \mu \mathrm{m}$ in length but only $0.6 \mu \mathrm{m}$ across its widest point. This ending is comparable in size and shape to many of the elongated ultrafine endings seen at the light level, such as those seen in Figure 8. Scale bars, $0.5 \mu \mathrm{m}$. Magnification: Figure 11, $\times 20,000$; Figure 12, × 21,100.

Figure 13. Highly elongated ultrafine primary endings also sit in the interior of glomeruli. The upper scalloped surface of this $4.2-\mu \mathrm{m}$-long primary ending contacts six small neural processes and synapses (oblique arrows) on two of them at the left. One of these is a $S$ spine. The primary ending contains numerous elliptical synaptic vesicles whose long diameters generally parallel the long axis of the ending as well as two dense core vesicles (arrowheads), elongated mitochondria $(M)$, and neurotubules (vertical arrows). Scale bar, $0.5 \mu \mathrm{m}$. Magnification $\times 34,300$.

Figure 14. In this glomerulus, the highly elongated HRP-filled primary ending is surrounded by the same kinds of neural processes which surround the shorter kinds of ultrafine primary endings, such as those in Figures 9 and 10 . These include a $S_{v}$ spine and a $P_{2}$ axonal ending. The inset shows a cluster of synaptic vesicles inside of the $P_{2}$ ending where it forms an axoaxonic synapse (arrow) on the primary ending. Magnification $\times 28,600$; inset, $\times 50,000$. Scale bar, $0.5 \mu \mathrm{m}$. 
generates most of its endings in lamina III (Light and Perl, 1979), the field receptor afferent which generates many endings in laminae III and IV (Light and Perl, 1979), the slowly adapting type I afferents (Brown et al., 1978) which generate most of their endings in lamina IV, the guard hair afferents with their flame-shaped arbors which ramify across lamina III and IV (Brown et al., 1977), the Pacinian corpuscle afferents which generate endings across laminae III to VI (Brown et al., 1980), the rapidly adapting afferents of glabrous skin with endings in laminae III (Brown et al., 1980), and the large la muscle afferents which generate their endings in the ventral horn (Brown and Fyffe, 1978; Burke et al., 1979). Each of these myelinated primary axons shares several features in common with the large caliber primary axons described in lamina I in this study: they each give rise to several, thin, branched, ending-bearing collaterals which are finer than their thicker parent branches; these ending-bearing branches, in turn, generate several relatively widely spaced large bulbous endings. The large caliber primary axons of lamina I described in this report closely match the morphological characteristics of the terminal arbors of the A $\delta$ high threshold mechanoreceptors in lamina I (Light and Perl, 1979) in terms of the morphology of their endings and their ending-bearing collaterals as well as in the frequent reversal of directions of their thicker parent branches.

The ultrafine primary axons differ from all of the above mentioned myelinated primary axons in two important respects. Their thin parent branches are the same caliber as those portions of the axons which bear endings and their endings are much finer and generally more closely spaced than those of the myelinated primary axons. The ultrafine and large caliber primary axons are considered to be two distinct populations of axons, not only on the basis of their morphological differences but also because an extensive examination of large numbers of ultrafine primary axons in lamina I and Lissauer's tract in Golgi preparations failed to provide any evidence that they originate from large caliber parent branches. In the same context, an examination of the terminal arbors of small myelinated $\mathrm{A} \delta$ high threshold mechanoreceptive primary axons in lamina I following intra-axonal injections of HRP (Light and Perl, 1979) revealed no branches resembling ultrafine primary axons. In addition, the extensive analyses of the laminar distribution of the many different kinds of small myelinated primary axons which arborize in the dorsal horn (Brown et al., 1977, 1978, 1980; Light and Perl, 1979) has shown that only the A $\delta$ high threshold mechanoreceptive primary axon generates endings in lamina I (Light and Perl, 1979). Physiological studies have described small myelinated cold thermoreceptive and heat nociceptive primary axons which terminate in the dorsal horn (see Price and Dubner, 1977 for review). However, these primary axons have not been found in the cat spinal dorsal horn. Therefore, the absence of other suitable small myelinated primary axonal candidates also points to the conclusion that the ultrafine axons in lamina I are part of the unmyelinated contingent of primary axons.

The presence of extremely fine primary endings in lamina $I$ was recognized first in axonal degeneration studies, i.e., in studies employing either trigeminal rhizotomy (Gobel and Hockfield, 1977) or peripheral nerve injuries in which the distal ends of primary axons were amputated by extirpating the pulps of teeth (Gobel and Binck, 1977). It was recognized in the latter study that these small endings in lamina I must belong to a primary axon which differed from those which gave rise to the large primary endings in lamina II since the small endings were the first to exhibit blackened degenerative changes following tooth pulp extirpations. It also was noted that the degenerative changes in these small primary endings occurred prior to the appearance of degenerative changes in myelinated axons in the spinal V (ract. On the basis of that observation, it was hypothesized that the small endings in lamina I were probably derived from unmyelinated primary axons. Now it is recognized that the degenerating small endings in the tooth pulp studies represented transverse views of ultrafine primary endings. The observation in this study that ultrafine primary endings are part of primary axons whose thin parent branches in Lissauer's tract are comparable in size to most of the unmyelinated axons in Lissauer's tract (Figs. 7 and 8) supports that hypothesis.

There is an impressive body of literature documenting the existence of fine unmyelinated primary axons that respond to nociceptive and thermal stimuli and conduct in the $\mathrm{C}$ range (see Burgess and Perl, 1973; Price and Dubner, 1977 for reviews). There is also considerable evidence documenting that the nociceptive and thermal inputs which are transmitted by these unmyelinated primary axons are conveyed to lamina I neurons (Christensen and Perl, 1970; Price and Mayer, 1975; Price et al., 1976, 1978, 1979; Dostrovsky and Hellon, 1978; J. M. Chung et al., 1979; Light et al., 1979; Bennett et al., 1981). One of the most important current questions concerning lamina I neurons relates to the routes by which they might receive these inputs. Since all lamina I neurons have the bulk of their dendritic arbors confined in lamina I (Gobel, 1978), two potential routes exist. First, C nociceptive and thermoreceptive primary axons could arborize in lamina I and transfer their inputs to lamina I neurons through direct monosynaptic connections. Second, these primary axons could terminate in deeper layers of the dorsal horn and transfer their inputs to excitatory interneurons which, in turn, transfer them to lamina I neurons. The finding of large numbers of ultrafine primary axons in lamina I strongly suggests that a significant part of the nociceptive and thermal inputs reaching lamina I neurons does so via the first route, i.e., through direct monosynaptic connections in lamina I. To date, small HRP-filled primary endings comparable to the ultrafine primary endings in lamina I have not been found in lamina II.

Synaptic connections. The ultrafine and large caliber primary endings in lamina I deliver their inputs to small caliber dendritic shafts and spine heads. There have been some suggestions that appreciable numbers of primary endings synapse on the cell bodies and basal dendrites of lamina I neurons (Narotzky and Kerr, 1978). The appearance of several primary endings in the vicinity of a lamina I cell body, as in Figure 4, could easily give the impression in the light microscope that axosomatic con- 

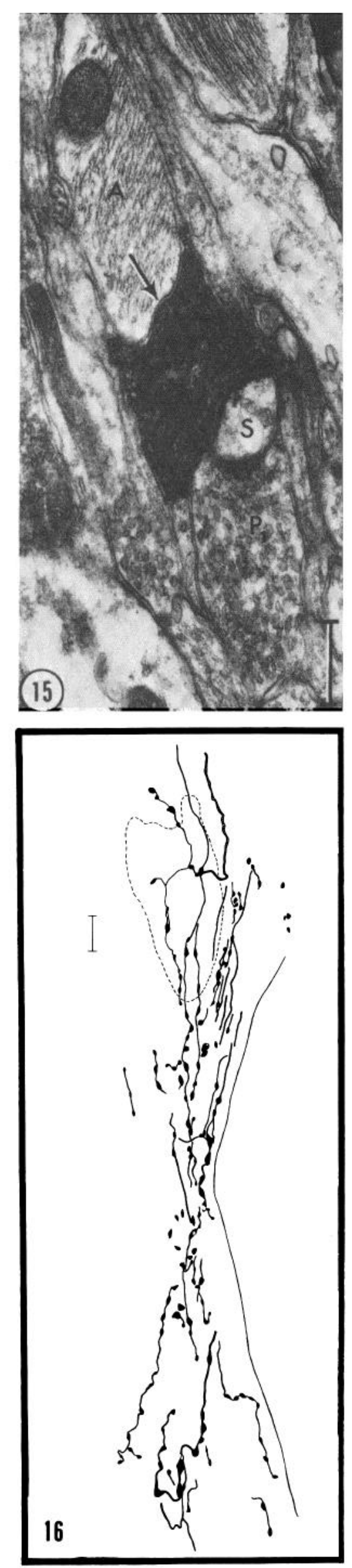

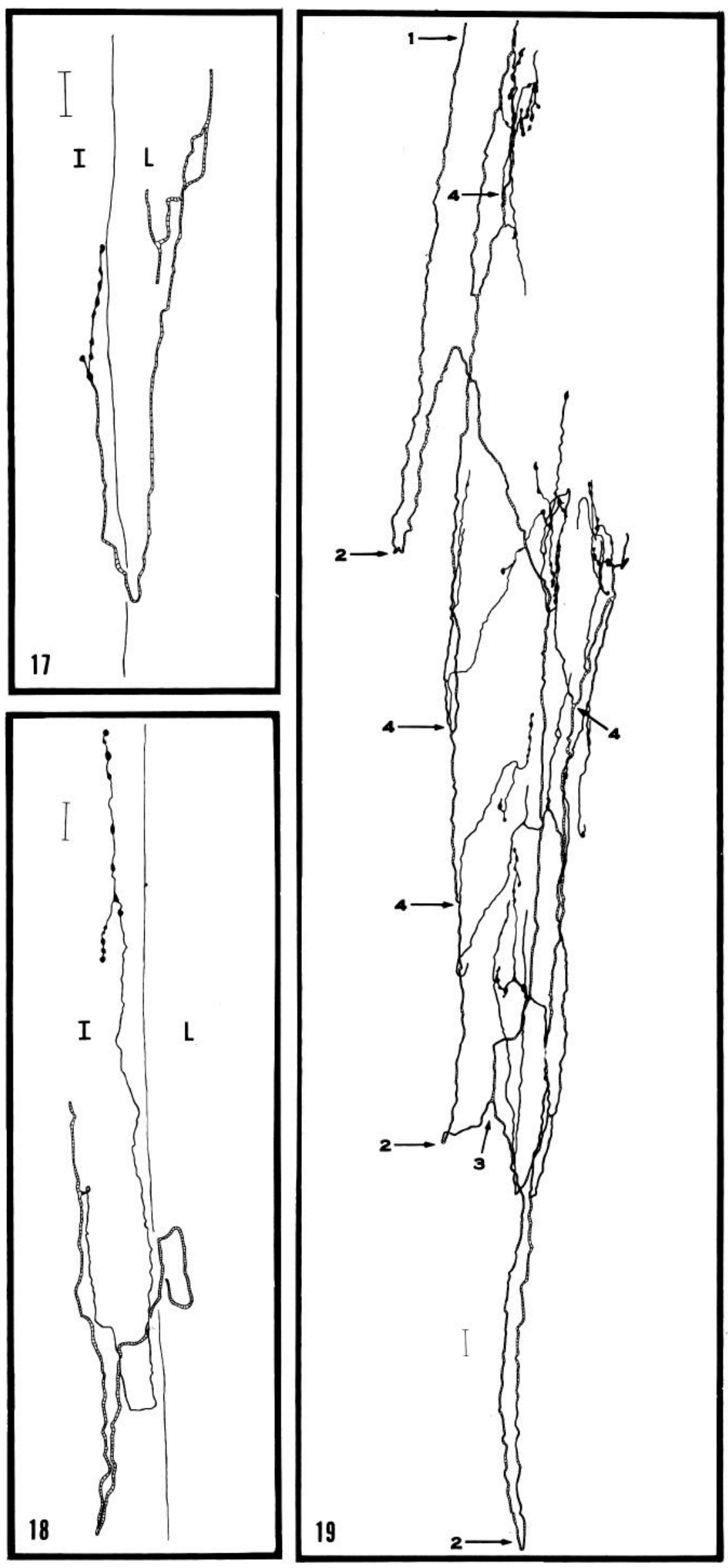


nections exist as in one of Ramon y Cajal's drawings of the dorsal horn (Fig. 110 in Ramon y Cajal, 1911). However, in this study, no primary endings were found synapsing on or even abutting a lamina I cell body. Recent. EM degeneration and EM autoradiographic studies (Ralston and Ralston, 1979) also did not find any evidence of axosomatic synapses by primary endings in lamina $I$. These observations do not support the claim by Narotzky and Kerr (1978) that $10 \%$ of the endings found on lamina I cell bodies are of primary axonal origin.

Spine heads without synaptic vesicles ( $\mathrm{S}$ spines) are the most frequently observed components of the ultrafine glomeruli and, generally, at least one of these can be seen in each glomerulus, especially if they have been sectioned serially (Figs, 9, 10, 13, and 16). A potential source of these $S$ spines is the many spiny lamina I neurons, such as the spiny pyramid (Gobel, 1978). Other potential sources of $\mathbf{S}$ spines are neurons in the deeper layers which send some of their dendrites into lamina I (Ramon y Cajal, 1895, 1911; Szentagothai, 1964; Gobel, 1974). One of the best ways to understand the synaptic events in the ultrafine glomeruli is to consider them from the vantage point of the S spines.

An S spine head receives its primary input from an ultrafine primary ending at a single axodendritic synapse (Fig. 22). The transfer of primary inputs to $S$ spines and their subsequent integration along dendritic shafts which bear the $\mathrm{S}$ spines can be modified in the ultrafine glomerulus from at least three different sources. The first of these are the dendrites with small aggregates of agranular synaptic vesicles in their spine $\left(S_{r}\right)$ heads (Figs. 9 and 22). These dendrites are the second most common processes in the ultrafine glomeruli. The laminar location of their cell bodies is unknown. Their synaptic vesicles are smaller than those found in the vesicle-containing (type 2) dendrites of the islet cells in lamina II (Gobel et al., 1980) and therefore are not thought to arise from these cells which sometimes send an occasional dendrite into lamina I. Their abundance in lamina I suggests that at least some probably originate from lamina I neurons. The recent demonstration of leucine-enkephalin immu- noreactivity in the dendrites of lamina I neurons also suggests that lamina I neurons may be a source of vesiclecontaining dendrites in lamina I which could influence primary afferent transmission (Glazer and Basbaum, 1981). The other sources (Fig. 22) are two kinds of $P$ axonal endings which form axoaxonic synapses on the ultrafine primary endings and axodendritic synapses on the $\mathrm{S}$ spine heads. These could arise from recurrent axon collaterals of lamina I neurons (Bennett et al., 1981) or from axons of neurons in the deeper layers of the dorsal horn. However, they are not thought to arise from the descending axons of serotonergic neurons in the brain stem (Ruda and Gobel, 1980; Ruda et al., 1981). Similar kinds of processes and synaptic connections prevail in the glomeruli built around large caliber primary endings, i.e., $S$ and $S_{v}$ spines, dendritic shafts, and $P$ endings (Figs. 20 and 21).

In order to appreciate the synaptic events in the ultrafine glomeruli fully, it is crucial to understand whether transmitter release from the $S_{v}$ spines and $P$ endings leads to a facilitation or an inhibition of the transfer of primary afferent inputs to the $\mathrm{S}$ spines and the dendritic shafts which receive axodendritic synapses from the primary ending (Fig. 22). On the basis of what has been learned about synaptic circuitry in other glomeruli in the dorsal horn and in several other locations in the central nervous system (see Gobel et al., 1980 for review), a twopart hypothesis is proposed. First, ultrafine primary endings transfer noxious and/or thermal inputs simultaneously to at least two kinds of neurons through their axodendritic synapses and one of these, i.e., the one with $\mathrm{S}$ spines, is a lamina I projection neuron whose axon leaves the dorsal horn and travels to other locations including the thalamus. Second, the neurons with the $S_{v}$ spines together with the $\mathrm{P}$ endings function to either inhibit or decrease the firing rate of the lamina I projection neurons with the $\mathbf{S}$ spines. They do this either postsynaptically through dendrodendritic and axodendritic synapses on the S spines or presynaptically through dendroaxonic and axoaxonic synapses on the ultrafine primary endings (Fig. 22).

Figure 15. Lamina I contains numerous, elliptical, filament-filled, astrocytic processes $(A)$. These are frequently found inside lamina I glomeruli where they are pressed into (arrow) scalloped depressions in the HRP-filled ultrafine primary endings. This transversely sectioned glomerulus also shows a $S$ spine and a $P_{1}$ axonal ending. Magnification $\times 36,600$. Scale bar, $0.5 \mu \mathrm{m}$.

Figure 16. Large primary endings as well as ultrafine primary endings are common in lamina I. This drawing illustrates all of the large HRP-filled primary endings visible in lamina I in a single 100- $\mu \mathrm{m}$-thick parasagittal section. The dashed enclosed area at the top circumscribes a deep axon bundle. Scale bar, $10 \mu \mathrm{m}$.

Figure 17. A thick parent branch (striped) of an HRP-filled primary axon branches twice and runs for $120 \mu \mathrm{m}$ in Lissauer's tract $(L)$. It then turns sharply at a hairpin turn and enters lamina $I(I)$ where it gives rise to a thin short collateral which bears several large endings near the outer border of lamina I. Scale bar, $10 \mu \mathrm{m}$.

Figure 18. In this parasagittal section of a Golgi specimen, a thick parent branch (striped) of a suspected primary axon which resembles the one in Figure 17 reverses direction twice in Lissauer's tract $(L)$ and once in lamina $I(I)$ before giving rise to a thin collateral. This collateral, after reversing direction and traveling for $200 \mu \mathrm{m}$ in lamina I, gives rise to several large endings. The thin collateral of these axons typically bifurcates when it begins generating its endings. The recurrent daughter branch is usually shorter and generates fewer endings than the other daughter branch. Scale bar, $10 \mu \mathrm{m}$.

Figure 19. The form of the large caliber primary axon of lamina I. This horizontal section of a Golgi specimen encompasses Lissauer's tract and lamina I. The thick parent branch (striped) is picked up dorsally in Lissauer's tract (arrow 1), followed for $134 \mu \mathrm{m}$ in its descent through Lissauer's tract where it reverses directions (arrows 2) at hairpin turns several times and branches (arrow 3). In lamina I, it gives rise to several thin collaterals (arrows 4). These collaterals generate large endings in three separate clusters. In each cluster, measurements made using the calibrated fine focus control show that endings lie within $12 \mu \mathrm{m}$ (top cluster), $29 \mu \mathrm{m}$ (middle cluster), and $39 \mu \mathrm{m}$ (bottom cluster) of each other in the transverse plane, i.e., at right angles to the page. These distances are well within the thickness of lamina I. Scale bar, $10 \mu \mathrm{m}$. 

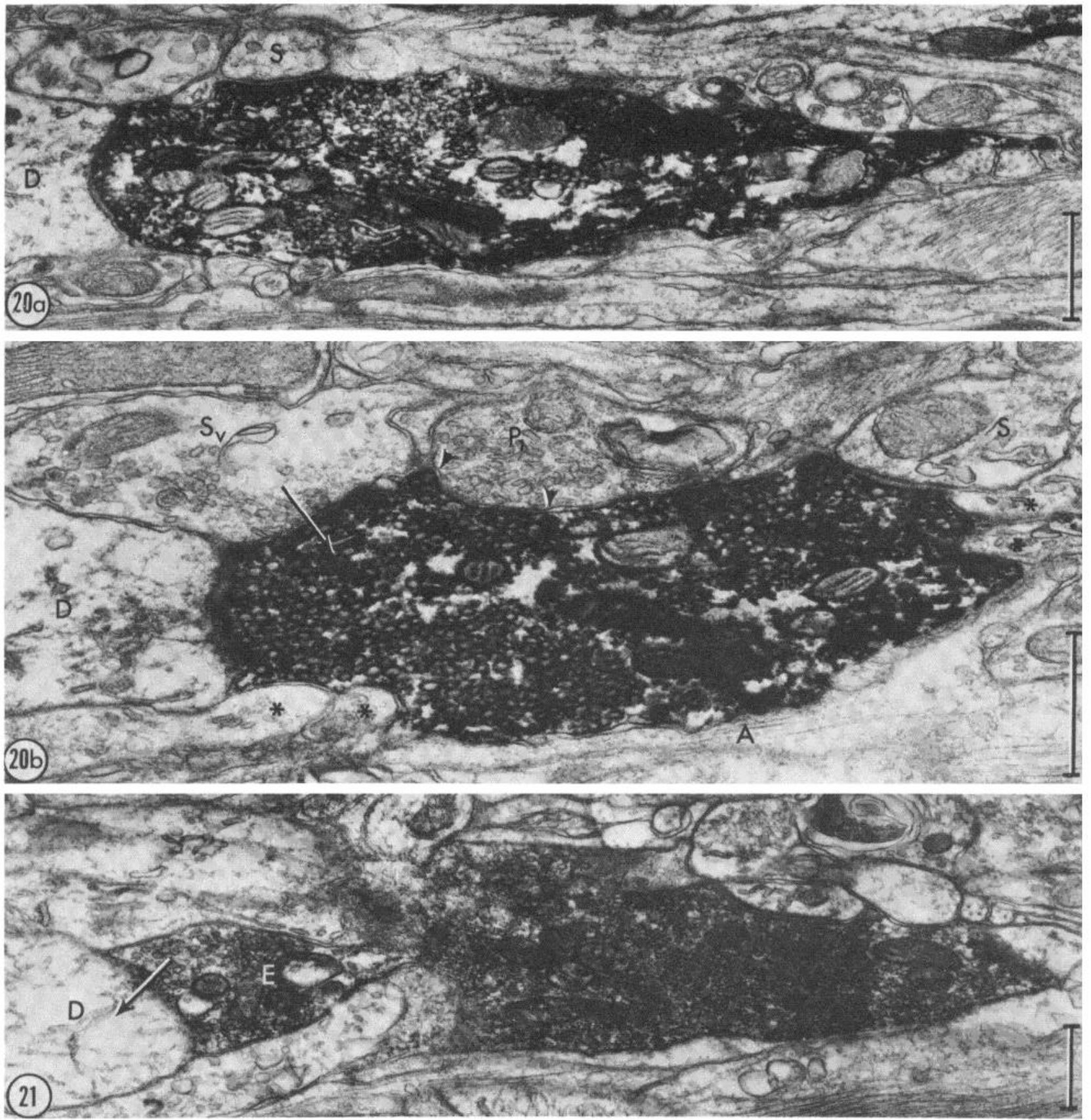

Figure 20. Two EM views through an HRP-filled large caliber primary ending whose dimensions and shape correspond to those of the large primary endings seen at the light level in Figures 16 to 19. In $a$, a large primary ending, like the ultrafine primary endings, sits in the interior of a glomerulus and is scalloped over an appreciable portion of its surface. The primary ending expands from a thin intervaricose segment at the right and synapses on a $S$ spine which is impressed into.its upper surface. It also synapses on a dendritic shaft $(D)$ which is partially visible at the left. In $b$, several neural processes are impressed into the scalloped primary ending. These include a $S_{v}$ spine which forms a dendroaxonic synapse (arrow) on the primary ending, a $S$ spine which receives a slightly asymmetrical synapse from the primary ending, a $P_{1}$ axonal ending which probably forms an axoaxonic synapse (between the arrowheads) on the primary ending, and other small unidentified neural processes (asterisks). Large caliber primary endings contain a mixture of different sized spherical and elliptical agranular synaptic vesicles. A sheet-like astrocytic process $(A)$ covers a portion of the primary ending. Scale bars, $0.5 \mu \mathrm{m}$. Magnification: $a, \times 32,800 ; b, \times 47,000$.

Figure 21. Some large caliber primary endings give rise to small spine-like extensions $(E)$ which also have neural processes, such as small dendritic shafts $(D)$, pressed into their surface. The arrow denotes the site of a probable axodendritic synapse on this shaft. These spine-like extensions are sometimes also visible at the light level as in Figure 2. Magnification $\times 26,400$. Scale bar, $0.5 \mu \mathrm{m}$. 


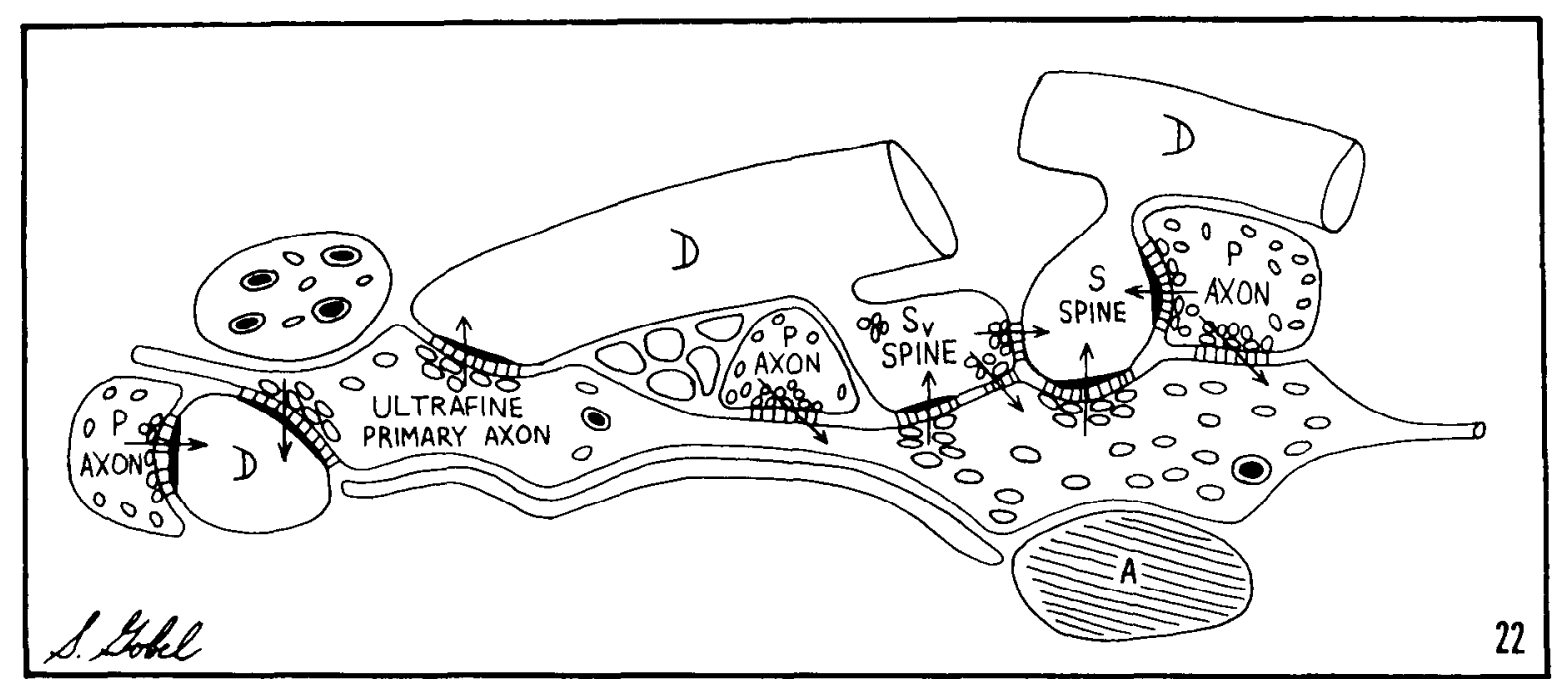

Figure 22. Summary of the components and synaptic connections of the ultrafine glomeruli in lamina I. The major neural processes surrounding the centrally situated ultrafine primary axon include small peripheral or $P$ axonal endings and three kinds of dendritic processes which receive axodendritic synapses (vertical arrows) from the ultrafine primary axon. These dendritic processes include spines with $\left(S_{\imath}\right)$ and without $(S)$ synaptic vesicles and shafts $(D)$. These surrounding processes are linked (horizontal arrows) by the following synapses: $S$ spines receive dendrodendritic synapses from $S_{t}$ spines and axodendritic synapses from $P$ endings; $P$ endings also form axodendritic synapses on dendritic shafts (left) but not on $S_{t}$. spines. Transmitter release from the ultrafine primary axon can be modified at the oblique arrows through the axoaxonic synapses of $P$ endings on the axonal endings and intervaricose segments of the ultrafine primary axons and through the dendroaxonic synapses of $S_{\imath}$ spines on the axonal endings of the ultrafine primary axon. Other constituents of ultrafine glomeruli include structures containing several dense core vesicles (upper left), filament-filled astrocytic processes $(A)$, sheet-like astrocytic processes (bottom) which cover appreciable portions of the ultrafine primary endings, and clusters of small unmyelinated axons. The large caliber primary endings in lamina I are surrounded by similar neural processes which are linked by similar kinds of axodendritic, axoaxonic, and dendroaxonic synapses.

Regarding the first part of this hypothesis, EM analyses of glomeruli in several locations outside of lamina I have either shown definitively or strongly suggested that scalloped afferent axonal endings in the interior of glomeruli invariably synapse on the dendrites of either a projection neuron, such as thalamocortical projection neurons in thalamic nuclei (Szentagothai et al., 1966; Guillery, 1964; Ralston, 1969; Wong-Riley, 1972) and the mitral cell in the olfactory bulb (Pinching and Powell, 1972), or on an excitatory interneuron whose axon leaves the layer where its cell body and dendrites reside, such as the cerebellar granule cell (Ramon y Cajal, 1911) or the stalked cell in lamina II of the dorsal horn (Gobel et al., 1980).

Regarding the second part of the hypothesis, these same EM studies have shown that scalloped afferent axons also synapse on the dendrites of inhibitory interneurons which, in turn, synapse on the dendrites of either the projection neuron or the excitatory interneuron. For example, in the olfactory glomeruli and in thalamic nuclei, scalloped afferent axons synapse on presumed inhibitory interneurons with synaptic vesicles in their dendrites which form dendrodendritic synapses on the projection neurons. In the cerebellar cortex, scalloped mossy fiber afferent endings synapse on the dendrites of the Golgi type II interneuron. These inhibitory interneurons, which have been implicated recently as using $\gamma$-aminobutyric acid as their neurotransmitter (McLaughlin et al., 1974), form axodendritic synapses on the granule cell dendrites. Finally, recent EM analyses of islet cells which had been filled intracellularly with HRP in lamina IIa of the dorsal horn have shown that these inhibitory interneurons contained synaptic vesicles in their dendrites and formed dendroaxonic synapses on the scalloped endings and dendrodendritic synapses on dendritic spines without synaptic vesicles in the lamina IIa glomeruli (Gobel et al., 1980). In that same study, it was shown that many of the spines without synaptic vesicles in the lamina IIa glomeruli belonged to stalked cells.

Having drawn these parallels between the ultrafine glomeruli in lamina I and glomeruli in other locations, it is worth noting that the dendroaxonic and axoaxonic synapses on the ultrafine primary axons (Fig. 22) may be especially effective in blocking the transfer of primary inputs to second order neurons because of the form of these primary axons. Most of the primary axons in the dorsal horn, such as the large caliber primary axons in lamina I (Figs. 17 to 19), as well as those in the deeper lamina bear relatively few endings on each ending-bearing collateral. In contrast, many of the ultrafine primary axons bear numerous endings on their long unbranched terminal strands (Figs. 6 to 8). A few dendroaxonic or axoaxonic synapses on either an ultrafine primary ending (Figs. 9, $a$ and $d$ and 14) or on an intervaricose segment of an ultrafine primary axon (Fig. 9a) might be sufficient to block the invasion of incoming action potentials or the electrotonic spread of graded potentials and thus either terminate or diminish transmitter release from all of the primary endings along the ultrafine strand. In contrast, such synapses on an ending-bearing collateral of a large 
caliber primary axon (Fig. 20b) may only alter transmitter release from the endings on that particular collateral which would only represent a small part of the total number of endings of that primary axon, e.g., Figure 19.

\section{References}

Adams, J. C. (1977) Technical considerations on the use of horseradish peroxidase as a neuronal marker. Neuroscience 2: 141-145.

Beal, J. A. (1979) The ventral dendritic arbor of marginal (lamina I) neurons in the adult primate spinal cord. Neurosci. Lett. 14: 201-206.

Beal, J. A., and C. A. Fox (1976) Afferent fibers in the substantia gelatinosa of the adult monkey (Macaca mulatta): A Golgi study. J. Comp. Neurol. 168: 113-144.

Beattie, M. S., J. C. Bresnahan, and J. S. King (1978) Ultrastructural identification of dorsal root primary afferent terminals after anterograde filling with horseradish peroxidase. Brain Res. 153: 127-134.

Bennett, G. J., M. Abdelmoumene, H. Hayashi, M. J. Hoffert, and R. Dubner (1981) Spinal cord layer I neurons with axon collaterals that generate local arbors. Brain Res. 209: 421426.

Brown, A. G., and R. E. W. Fyffe (1978) The morphology of group Ia afferent fiber collaterals in the spinal cord of the cat. J. Physiol. (Lond.) 274: 111-127.

Brown, A. G., P. K. Rose, and P. J. Snow (1977) The morphology of hair follicle afferent collaterals in the spinal cord of the cat. J. Physiol. (Lond.) 272: 779-797.

Brown, A. G., P. K. Rose, and P. J. Snow (1978) Morphology and organization of axon collaterals from afferent fibers of slowly adapting type I units in cat spinal cord. J. Physiol. (Lond.) 277: 15-27.

Brown, A. G., R. E. W. Fyffe, and R. Noble (1980) Projections from Pacinian corpuscles and rapidly adapting mechanoreceptors of glabrous skin to the cat's spinal cord. J. Physiol. (Lond.) 307: 385-400.

Burgess, P. R., and E. R. Perl (1973) Cutaneous mechanoreceptors and nociception. In Handbook of Sensory Physiology, Somatosensory System, A. Iggo, ed., Vol. 2, pp. 29-78, Springer-Verlag, Heidelberg.

Burke, R. E., B. Wamsley, and J. A. Hodgson (1979) HRP anatomy of group Ia afferent contacts on alpha motoneurons. Brain Res. 160: 347-352.

Christensen, B. N., and E. R. Perl (1970) Spinal neurons specifically excited by noxious or thermal stimuli: Marginal zone of the dorsal horn. J. Neurophysiol. 33: 293-307.

Chung, J. M., D. R. Kenshalo, Jr., K. D. Gerhart, and W. D. Willis (1979) Excitation of primate spinothalamic neurons by cutaneous C-fiber volleys. J. Neurophysiol. 42: 1354-1369.

Chung, K., L. A. Langford, A. E. Applebaum, and R. E. Coggeshall (1979) Primary afferent fibers in the tract of Lissauer in the rat. J. Comp. Neurol. 184: 587-598.

Dostrovsky, J. O., and R. F. Hellon (1978) The representation of facial temperature in the caudal trigeminal nucleus of the cat. J. Physiol. (Lond.) 277: 29-47.

Glazer, E. J., and A. I. Basbaum (1981) Immunocytochemical localization of leucine-enkephalin in the spinal cord of the cat: Enkephalin-containing marginal neurons and pain modulation. J. Comp. Neurol. 196: 377-389.

Gobel, S. (1974) Synaptic organization of the substantia gelatinosa glomeruli in the spinal trigeminal nucleus of the adult cat. J. Neurocytol. 3: 219-243.

Gobel, S. (1976) Dendroaxonic synapses in the substantia gelatinosa glomeruli of the spinal trigeminal nucleus of the cat. J. Comp. Neurol. 167: 165-176.

Gobel, S. (1978) Golgi studies of the neurons in layer I of the dorsal horn of the medulla (trigeminal nucleus caudalis). J. Comp. Neurol. 180: 375-394.

Gobel, S. (1979) Neural circuitry in the substantia gelatinosa of Rolando: Anatomical insights. In Advances in Pain Research and Therapy, J. J. Bonica, J. C. Liebeskind, and D. G. AlbeFessard, eds., Vol. 3, pp. 175-195, Raven Press, New York.

Gobel, S., and J. M. Binck (1977) Degenerative changes in primary trigeminal axons and in neurons in nucleus caudalis following tooth pulp extirpations in the cat. Brain Res. 132: 347-354.

Gobel, S., and W. M. Falls (1979) Anatomical observations of horseradish peroxidase filled terminal primary axonal arborizations in layer II of the substantia gelatinosa of Rolando. Brain Res. 175: 335-340.

Gobel, S., and S. Hockfield (1977) An anatomical analysis of the synaptic circuitry of layers I, II and III of trigeminal nucleus caudalis in the cat. In Pain in the Trigeminal Region, D. J. Anderson and B. Matthews, eds., pp. 203-211, Elsevier/ North Holland Biomedical Press, Amsterdam.

Gobel, S., W. M. Falls, G. J. Bennett, M. Abdelmoumene, H. Hayashi, and E. Humphrey (1980) An EM analysis of the synaptic connections of horseradish peroxidase-filled stalked cells and islet cells in the substantia gelatinosa of adult cat spinal cord. J. Comp. Neurol. 194: 781-808.

Gobel, S., S. Hockfield, and M. A. Ruda (1981) An anatomical analysis of the similarities between medullary and spinal dorsal horns. In Oral-Facial Sensory and Motor Mechanisms: International Symposium on Oral Physiology, Y. Kawamura and R. Dubner, eds., Quintessence, Tokyo, in press.

Guillery, R. W. (1964) The organization of synaptic interconnections in the laminae of the dorsal lateral geniculate nucleus of the cat. Z. Zellforsch. Mikrosk. Anat. 96: 1-38.

Hockfield, S., and S. Gobel (1978) Neurons in and near nucleus caudalis with long ascending projection axons demonstrated by retrograde labeling with horseradish peroxidase. Brain Res. 139: 333-339.

Kumazawa, 'T'., and E. R. Perl (1978) Excitation of marginal and substantia gelatinosa neurons in the primate spinal cord: Indications of their place in dorsal horn functional organization. J. Comp. Neurol. 177: 417-434.

La Motte, C. (1977) Distribution of the tract of Lissauer and the dorsal root fibers in the primate spinal cord. J. Comp. Neurol. 172: 529-562.

Light, A. R., and E. R. Perl (1977) Differential termination of large-diameter and small-diameter primary afferent fibers in the spinal dorsal gray matter as indicated by labeling with horseradish peroxidase. Neurosci. Lett. 6: 59-63.

Light, A. R., and E. R. Perl (1979) Spinal termination of functionally identified primary afferent neurons with slowly conducting myelinated fibers. J. Comp. Neurol. 186: 117-132.

Light, A. R., D. L. Trevino, and E. R. Perl (1979) Morphological features of functionally defined neurons in the marginal zone and substantia gelatinosa of the spinal dorsal horn. J. Comp. Neurol. 186: 133-155.

McLaughlin, B. J., J. G. Wood, K. Saito, R. Barber, J. E. Vaughn, E. Roberts, and J. -Y. Wu (1974) The fine structure of glutamate decarboxylase in synaptic terminals of rodent cerebellum. Brain Res. 76: 377-391.

Narotzky, R. A., and F. W. L. Kerr (1978) Marginal neurons of the spinal cord: Types, afferent synaptology and functional considerations. Brain Res. 139: 1-20.

Pinching, A. J., and T. P. S. Powell (1972) A study of terminal degeneration in the olfactory bulb of the rat. J. Cell Sci. 10: 585-619.

Price, D. D., and R. Dubner (1977) Neurons that subserve the sensory-discriminative aspects of pain. Pain 3: 307-338.

Price, D. D., and D. J. Mayer (1975) Neurophysiological char- 
acterization of the anterolateral quadrant neurons subserving pain in $M$. mulatta. Pain 1: 59-72.

Price, D. D., R. Dubner, and J. W. Hu (1976) Trigeminothalamic neurons in nucleus caudalis responsive to tactile, thermal, and nociceptive stimulation of monkey's face. J. Neurophysiol. 39: 936-953.

Price, D. D., R. L. Hayes, M. A. Ruda, and R. Dubner (1978) Spatial and temporal transformations of input to spinothalamic tract neurons and their relation to somatic sensations. J. Neurophysiol. 41: 933-947.

Price, D. D., H. Hayashi, R. Dubner, and M. A. Ruda (1979) Functional relationships between neurons of the marginal and substantia gelatinosa layers of the primate dorsal horn. J. Neurophysiol. 42: 1590-1608.

Proshansky, E., and M. D. Egger (1977) Staining of dorsal root projection to the cat's dorsal horn by anterograde movement of horseradish peroxidase. Neurosci. Lett. 5: 103-110.

Ralston, H. J., III (1969) The synaptic organization of lemniscal projections to the ventrobasal thalamus of the cat. Brain Res. 14: 99-115.

Ralston, H. J., III, and D. D. Ralston (1979) The distribution of dorsal root axons in laminae I, II and III of the Macaque spinal cord: A quantitative electron microscope study. J. Comp. Neurol. 184: 643-684.

Kamon y Cajal, S. (1895) La fine anatomie de la moelle epiniere.
In Atlas der pathologischen Histologie des Nervensystems, Vol. 4, pp. 1-35, Hirschwaid, Berlin.

Ramon y Cajal, S. (1911) Histologie du Systems Nerveus de l'Homme et des Vertebres, Vols. I and II (1952 reprint), Instituto Ramon y Cajal, Madrid.

Rexed, B. (1952) The cytoarchitectonic organization of the spinal cord in the cat. J. Comp. Neurol. 96: 415-496.

Ruda, M. A., and S. Gobel (1980) Ultrastructural characterization of axonal endings in the substantia gelatinosa which take up $\left[{ }^{3} \mathrm{H}\right]$ serotonin. Brain Res. 184: 57-83.

Ruda, M. A., B. Allen, and S. Gobel (1981) Ultrastructural analysis of serotonergic medial brainstem afferents to the superficial dorsal horn. Brain Res. 205: 175-180.

Szentagothai, J. (1964) Neuronal and synaptic arrangement in the substantia gelatinosa Rolandi. J. Comp. Neurol. 122: 219234.

Szentagothai, J., J. Hamori, and T. Tombol (1966) Degeneration and electron microscope analysis of the synaptic glomeruli in the lateral geniculate body. Exp. Brain Res. 2: 283-301.

Willis, W. D., D. R. Kenshalo, Jr., and R. B. Leonard (1979) The cells of origin of the primate spinothalamic tract. J. Comp. Neurol. 188: 543-574.

Wong-Riley, M. T. T. (1972) Terminal degeneration and glial reactions in the lateral geniculate nucleus of the squirrel monkey after eye removal. J. Comp. Neurol. 144: 61-92. 